\title{
PULMONARY RESECTION FOR METASTATIC COLORECTAL CANCER: EXPERIENCES WITH 159 PATIENTS
}

Shinji Okumura, MD

Haruhiko Kondo, MD

Masahiro Tsuboi, MD

Haruhiko Nakayama, MD

Hisao Asamura, MD

Ryosuke Tsuchiya, MD

Tsuguo Naruke, MD

\begin{abstract}
We reviewed the clinical courses of 159 patients between February 1967 and May 1995 for the purpose of examining the survival of patients who had pulmonary resection for metastatic colorectal cancer. The cumulative survivals at 5 years and 10 years were $40.5 \%$ and $27.7 \%$, respectively. Fifteen patients $(10 \%)$ were alive more than 10 years after the thoracotomy without any evidence of recurrence. The cumulative survival at 5 years for 39 patients who had hepatic metastases before thoracotomy was $33 \%$. There was a statistically significant difference in survival between patients with extrapulmonary metastases and those with only intrapulmonary metasta= ses before thoracotomy. The number of pulmonary metastases and the presence of hilar or mediastinal lymph node metastases affected postthoracotomy survival. There was no significant difference in survival on the basis of sex, age, location of the primary cancer, size of the pulmonary tumors, mode of operation, or disease-free interval. Surgical treatment for pulmonary metastases from colorectal cancer in selected patients, even those who had hepatic metastases before thoracotomy, might improve prognosis. (J Thorac Cardiovasc Surg 1996;112:867-74)
\end{abstract}

Qurgical therapy has been attempted for meta$O_{\text {static lung tumors since Thomford, Woolner, }}$ and Clagett $^{1}$ published the principles for surgical treatment of metastatic lung tumors in 1965. As for resection of pulmonary metastases from colorectal cancer, documented 5-year survivals after resection of pulmonary metastases varied among institutions, ranging from $22 \%$ to $42 \% .^{2-10} \mathrm{We}^{7}$ also reported our experience with 62 patients who underwent resection of pulmonary metastases from colorectal cancer in 1988. In that series, we could not show that surgical resection of pulmonary metastases improved the cure rate. Furthermore, the significance of pulmonary metastatectomy for patients who had hepatic metastases before thoracotomy was unknown. In the present series, the clinical courses of 159 patients were reviewed and followed for a much longer time. In addition, this study included 39

From the Division of Thoracic Surgery, National Cancer Center Hospital, 1-1, Tsukiji 5-chome, Chuo-ku, Tokyo, 104, Japan.

Received for publication Nov. 21, 1995; revisions requested Jan. 9, 1996; revisions received April 8, 1996; accepted for publication May 17, 1996.

Address for reprints: Haruhiko Kondo, MD, Division of Thoracic Surgery, National Cancer Center Hospital, 1-1, Tsukiji

5-chome, Chuo-ku, Tokyo 104, Japan.

Copyright (C) 1996 by Mosby-Year Book, Inc.

$0022-5223 / 96 \$ 5.00+0 \quad \mathbf{1 2 / 1 / 7 5 2 0 2}$ patients who had hepatic metastases before thoracotomy. Therefore we believe it is possible to examine the significance of pulmonary resection for metastatic colorectal cancer more accurately than in our previous report.

\section{Patients and methods}

A total of 162 patients underwent pulmonary resection for metastatic lesions from colorectal cancer between February 1967 and May 1995 in the National Cancer Center Hospital in Japan. There were three hospital deaths within 30 days of the operation, and 159 patients were available for review in this study. Criteria for resection of pulmonary metastases were as follows: (1) The patient must be able to tolerate the required surgical procedure and the remaining respiratory function is considered to be good enough for ordinary life. (2) Unilateral or bilateral lung lesions can be seen on a chest roentgenogram or a computed tomographic scan and those lesions presumably could be completely resected. (3) There are no distant metastases without pulmonary lesions and there was no evidence of local recurrence of the primary cancer. (4) It is possible to completely remove both hepatic and pulmonary metastases, if present.

Table I summarizes the characteristics of the 159 patients. We divided the patients into three groups. Group $A$ consisted of 111 patients who had no extrapulmonary metastatic lesions before thoracotomy. Group B included 39 patients who had hepatic metastases before or at the time of thoracotomy. Ten patients who underwent simultaneous resection of pulmonary and hepatic metastases were included in group B. Group C was composed of nine 
Table I. Characteristics of 159 patients who underwent resection of pulmonary metastases from colorectal cancer

\begin{tabular}{|c|c|}
\hline & No. of patients \\
\hline \multicolumn{2}{|l|}{ Sex } \\
\hline Male & 95 \\
\hline Female & 64 \\
\hline \multicolumn{2}{|l|}{ Age (yr) } \\
\hline Average & 58.7 \\
\hline Range & $28-82$ \\
\hline \multicolumn{2}{|l|}{ Location of primary cancer } \\
\hline Colon & 82 \\
\hline Ascending & 19 \\
\hline Transverse & 4 \\
\hline Descending & 4 \\
\hline Sigmoid & 55 \\
\hline Rectum & 73 \\
\hline Unknown & 4 \\
\hline \multicolumn{2}{|l|}{ Grade of primary tumor } \\
\hline Dukes' A & 11 \\
\hline Dukes' B & 30 \\
\hline Dukes' C & 64 \\
\hline Unknown & 54 \\
\hline \multicolumn{2}{|l|}{ No. of Pulmonary metastases } \\
\hline Solitary & 107 \\
\hline Multiple & 52 \\
\hline \multicolumn{2}{|c|}{ Site of metastases before thoracotomy } \\
\hline No metastases (group A) & 111 \\
\hline Liver (group B) & 39 \\
\hline Local (group C) & 9 \\
\hline \multicolumn{2}{|l|}{ Location of pulmonary metastases } \\
\hline Left lung & 65 \\
\hline Right lung & 62 \\
\hline Both & 32 \\
\hline \multicolumn{2}{|l|}{ Mode of operation } \\
\hline Pneumonectomy & 7 \\
\hline Lobectomy & 85 \\
\hline Wedge or segmental resection & 67 \\
\hline
\end{tabular}

patients who had undergone resection of local recurrence before thoracotomy (Table I).

The medical charts were examined for age; sex; stage and grade of the primary cancer; location, number, and size of the pulmonary metastases; mode of the operation (Table I). Also evaluated were the presence of hepatic metastasis or local recurrence (or both) and disease-free interval (DFI) between resection of the primary lesion and clinical detection of pulmonary metastases. The survival after thoracotomy was estimated by the method of Kaplan and Meier. ${ }^{11}$ The significance of each prognostic factor was determined by the log-rank test. ${ }^{12}$

\section{Results}

Five of the 159 patients (3.1\%) underwent incomplete resection for pulmonary metastases because of numerous small lesions (four patients) or involvement of the main bronchus by metastatic lymph nodes (one patient).
The cumulative survivals at 5 years and 10 years were $40.5 \%$ and $27.7 \%$, respectively (Fig. 1). Fifteen of the 1610 -year survivors were alive with no evidence of cancer recurrence and only one patient died of metastatic disease. Seven of the 37 patients who survived more than 5 years died of metastatic disease, and five patients died without recurrence. Two patients were alive with recurrent cancer at the time of this report. The other 235 -year survivors were free of disease.

Table II shows survivals 5 years after thoracotomy based on potential prognostic factors. The cumulative survival for patients in group A was $44.9 \%$ at 5 years, but for patients in group B it was $33.0 \%$. The difference between these two groups was statistically significant. The cumulative survival for patients in group $\mathrm{C}$ at 5 years was $25.0 \%$. There was also a statistically significant difference between group A and group $\mathrm{C}$ but no significant difference between group B and group C (Table II, Fig. 2).

In group $A$, the cumulative survival for 78 patients with a solitary pulmonary metastasis was $52.5 \%$ at 5 years, whereas that for 33 patients with multiple pulmonary metastases was $25.5 \%$ (Fig. 3). The difference between these two groups was statistically significant $(p=0.019)$. Wedge or segmental resection was adopted to preserve respiratory function, especially in the patients with multiple metastases. Fourteen patients ( $42 \%$ ) with multiple metastases in group A underwent limited resection, 16 patients (49\%) had lobectomy, and three patients (9\%) had pneumonectomy. Among the patients with a solitary metastasis in group A, 23 patients $(29 \%)$ underwent limited resection, $52(66 \%)$ had lobectomy, and three (4\%) pneumonectomy. For the patients with a solitary metastasis, the cumulative survivals for the lobectomy and limited resection groups were $45.6 \%$ and $73.3 \%$, respectively, at 5 years $(p=0.080)$ (Fig. 4). The intrapulmonary recurrence rates after limited resection for the patients with multiple tumors and a solitary tumor were 50\% (7/14) and 39\% (9/23), respectively. In this series, we could not examine marginal recurrence after limited pulmonary resection. The cumulative survival for $52 \mathrm{pa}$ tients with a DFI of more than 24 months was $50.1 \%$ at 5 years, whereas that for 57 patients with a DFI of less than 24 months was $40.6 \%$. There was no significant difference in survival based on DFI for the patients in group A $(p=0.486)$.

In group $B$, the 5-year survival even for the patients who had hepatic metastases before thoracotomy was $33.0 \%$. Twenty patients had a solitary 


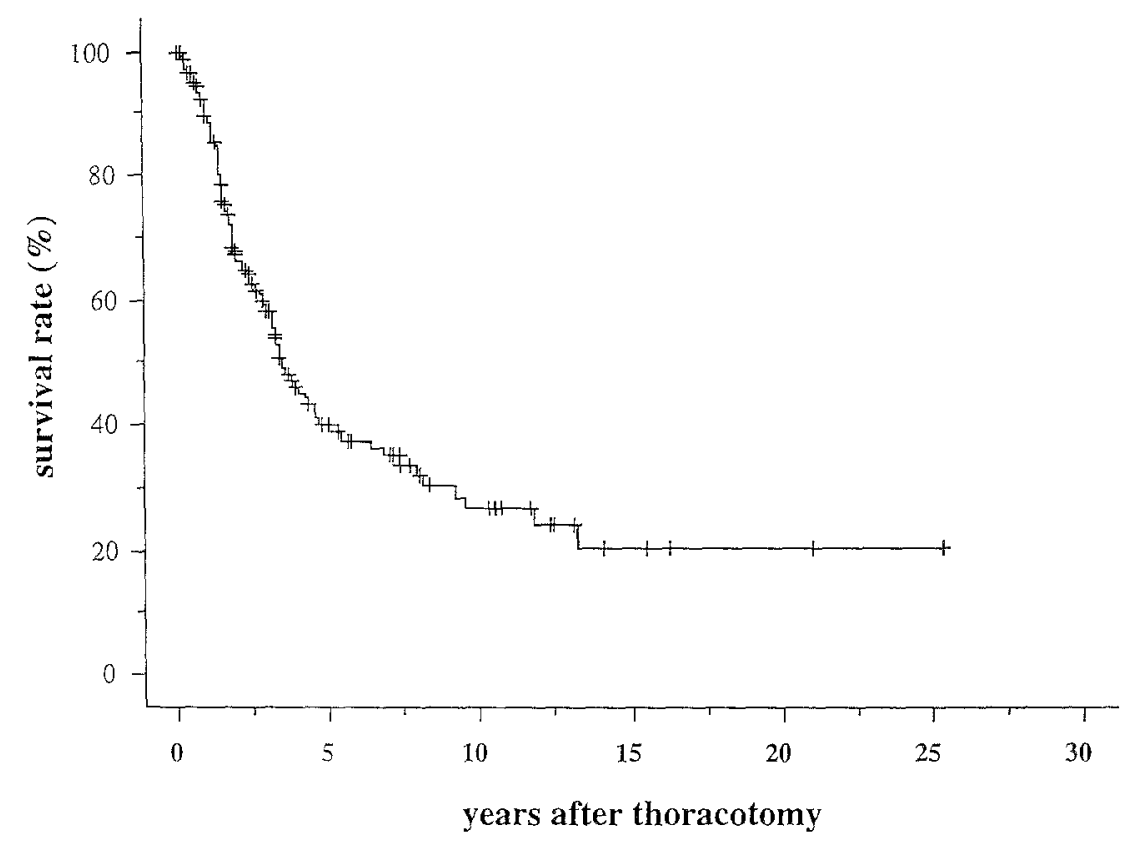

Fig. 1. Kaplan-Meier survival curve for all 159 patients who underwent resection of pulmonary metastases from colorectal cancer.

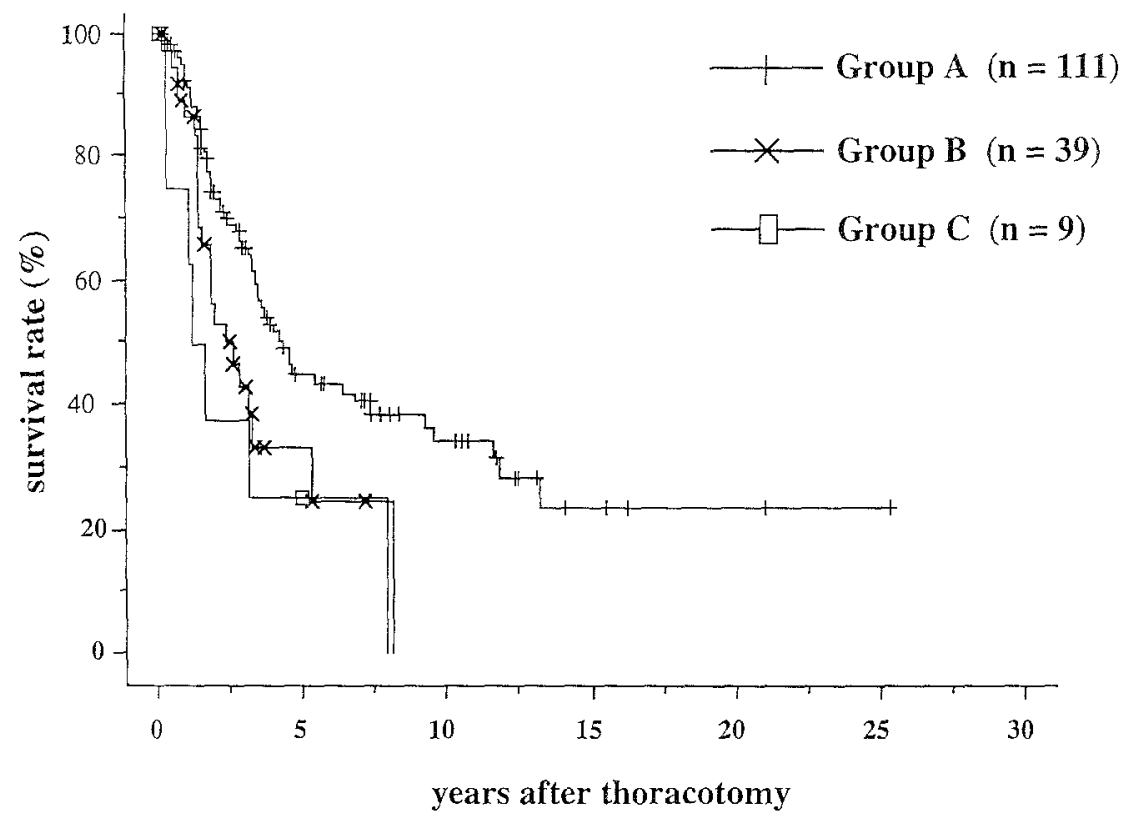

Fig. 2. Kaplan-Meier survival curves based on the three groups. Group A, Patients without extrathoracic metastasis before thoracotomy. Group B, Patients with a history of hepatic metastases. Group C, Patients with a history of local recurrences. $n$, Number of patients.

hepatic metastasis, three patients had two hepatic metastases, and four patients had three. In 12 patients the number of hepatic metastases was unknown. There was no significant difference in the survivals between the group of the patients with solitary hepatic metastases and those with multiple metastases $(p=0.26)$. Two of the four patients who survived more than 5 years died of metastatic dis- 


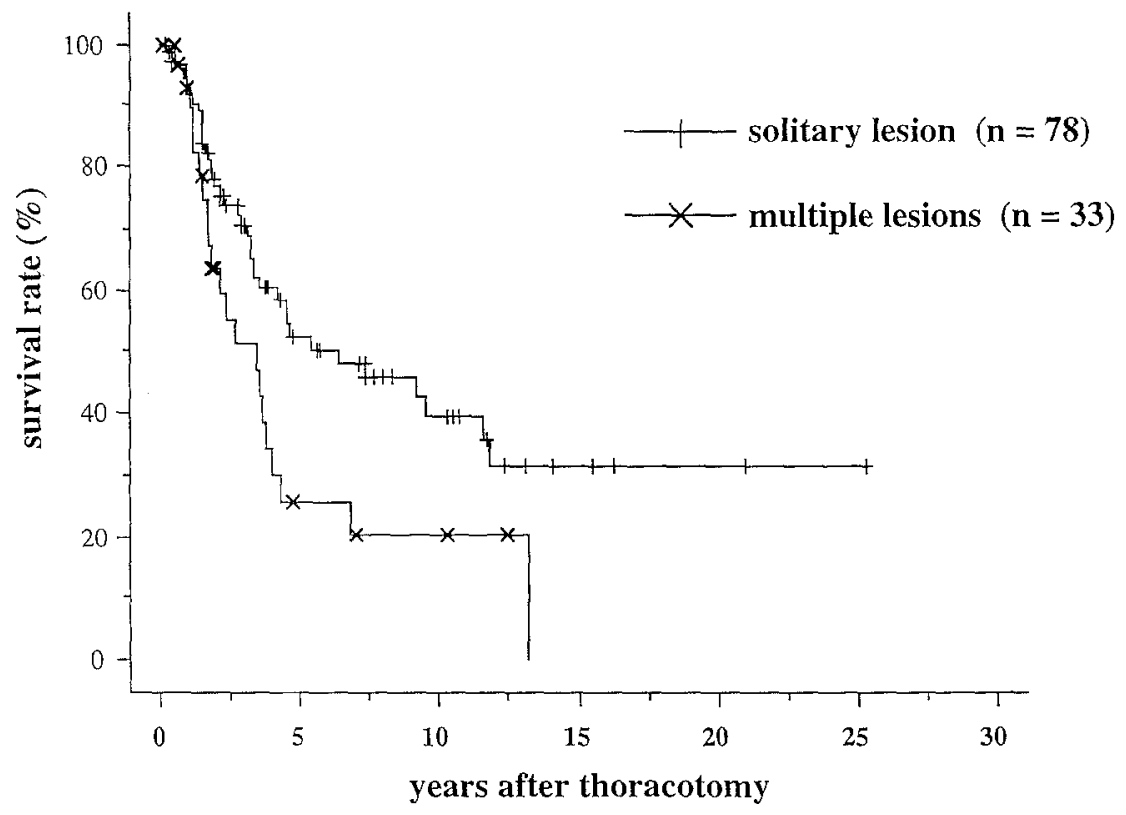

Fig. 3. Kaplan-Meier survival curves for the patients with a solitary metastasis and the patients with multiple metastases in group A $(p=0.019)$.

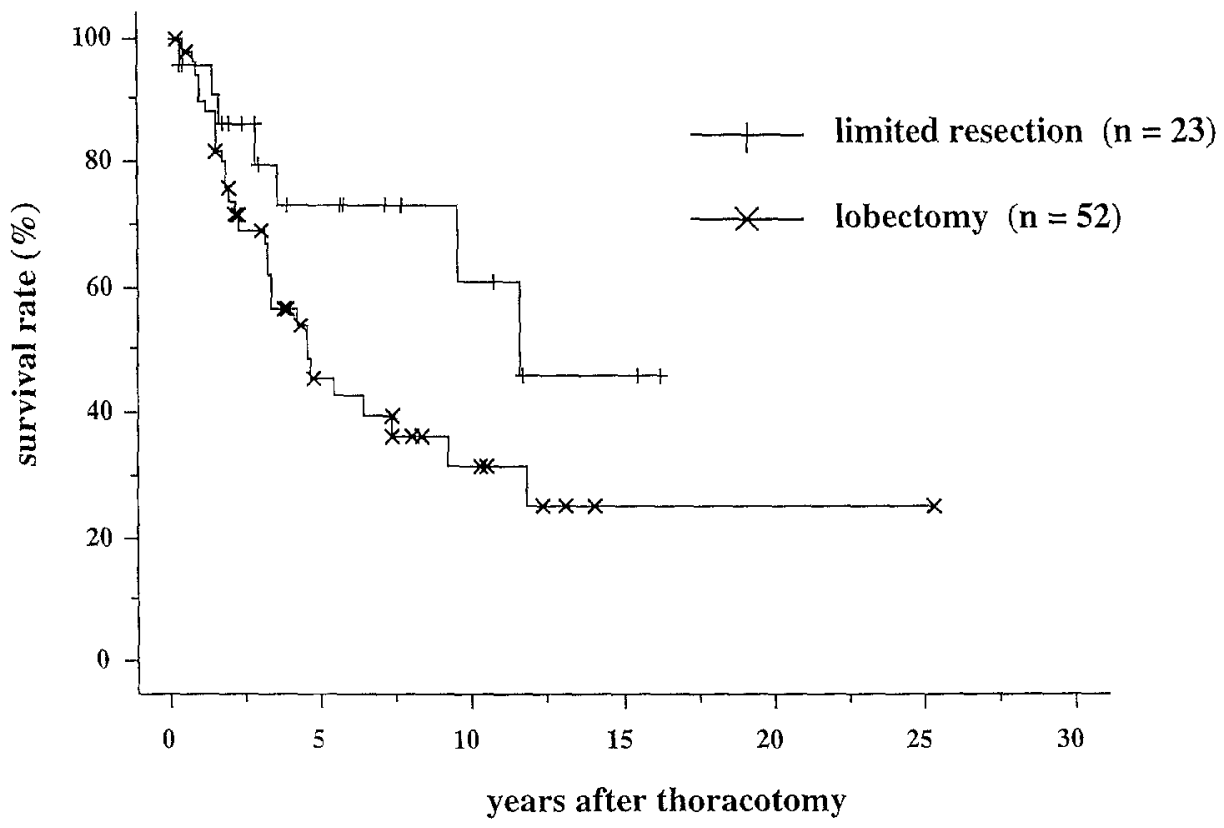

Fig. 4. Kaplan-Meier survival curves for the patients who underwent limited resection and the patients who underwent lobectomy in group A with a solitary metastasis $(p=0.08)$. $n$, number of patients.

ease and one patient was alive with recurrent cancer. The other patient was free of disease. The only statistically significant difference in survival for the patients in group $B$ was that concerning the number of pulmonary metastases. The cumulative survival for 22 patients with a solitary pulmonary metastasis was $43.7 \%$ at 5 years, whereas that for 17 patients with multiple pulmonary metastases in group B was $22.3 \%(p=0.047)$.

In this series, hilar or mediastinal lymph nodes of 
Table II. Survivals 5 years after thoracotomy on the basis of potential prognostic factors

\begin{tabular}{|c|c|c|c|}
\hline Variables & No. of patients & $\begin{array}{c}\text { Five year sumival } \\
(\%)\end{array}$ & $p$ Value \\
\hline \multicolumn{4}{|l|}{ Sex } \\
\hline Male & 95 & 37.3 & 0.639 \\
\hline Female & 64 & 46.1 & \\
\hline \multicolumn{4}{|l|}{ Age } \\
\hline$\geq 65 \mathrm{yr}$ & 52 & 55.9 & 0.222 \\
\hline$<65 \mathrm{yr}$ & 107 & 34.0 & \\
\hline \multicolumn{4}{|l|}{ Location of primary cancer } \\
\hline Colon & 82 & 42.1 & 0.801 \\
\hline Rectum & 73 & 39.1 & \\
\hline \multicolumn{4}{|l|}{ Grade of primary tumor } \\
\hline Dukes' A & 11 & $\pm[74.1]^{*}$ & $0.033^{*}$ \\
\hline Dukes' B & 30 & F 35.2 & $0.488 \dagger$ \\
\hline Dukes' C & 64 & {$[32.5]^{t}$} & $0.011+$ \\
\hline \multicolumn{4}{|c|}{ Site of metastases before thoracotomy } \\
\hline No metastases (group A) & 111 & $44.97 *$ & $0.009^{*}$ \\
\hline Liver (group B) & 39 & $\neq 33.0\}$ & $0.282 \dagger$ \\
\hline Local (group C) & 9 & $25.0]^{\dagger}$ & $0.012 \ddagger$ \\
\hline \multicolumn{4}{|l|}{ Size of metastatic lesion ${ }^{a}$} \\
\hline$\geq 3.0 \mathrm{~cm}$ & 73 & 35.3 & 0.078 \\
\hline$<3.0 \mathrm{~cm}$ & 79 & 46.8 & \\
\hline \multicolumn{4}{|l|}{ No. of pulmonary metastases } \\
\hline Solitary & 107 & 48.4 & 0.003 \\
\hline Multiple & 52 & 23.4 & \\
\hline \multicolumn{4}{|l|}{ Mode of operation } \\
\hline Wedge or segmental resection & 67 & $*[46.7]^{*}$ & $0.489^{*}$ \\
\hline Lobectomy & 85 & 39.8 & $0.572 \dagger$ \\
\hline Pneumonectomy & 7 & $47.6]$ & $0.703+$ \\
\hline \multicolumn{4}{|c|}{$\begin{array}{l}\text { Hilar and/or mediastinal lymph nodes } \\
\text { metastases }^{\mathrm{b}}\end{array}$} \\
\hline Negative & 85 & 50.0 & 0.0004 \\
\hline Positive & 15 & 6.7 & \\
\hline
\end{tabular}

"The size was unknown in seven patients.

${ }^{b}$ Lymph node involvement was not assessed in 59 patients.

$*,+,+$, The $p$ value with each symbol indicates the statistical comparison of survival between the corresponding two groups with the symbol out of three.

100 patients were dissected or sampled and lymph node metastasis from the pulmonary metastases was observed in 15 patients (Table II). One of these 15 patients was alive after more than 5 years, but she had been receiving chemotherapy for bone metastasis. The other 14 patients died of metastatic disease within 5 years after the thoracotomy. There was a statistically significant difference in survival between the patients who had hilar or mediastinal lymph node metastases and those who did not (Fig. 5).

Although the number of patients whose primary cancer was Dukes' grade A was small (11/159), the 5-year survival for these patients was $74.1 \%$. Dukes' A classification was a favorable prognostic factor (Table II).

$\mathrm{We}^{7}$ previously reported that there is a significant difference in survival on the basis of the size of pulmonary metastatic lesions, but in this series the size of the metastatic tumor had no significant bearing on the survival (Fig. 6). No significant differences in survival were based on sex, age, location of the primary lesion, or extent of the operation (Table II).

In this series, there were three favorable prognostic factors or criteria: (1) The lung should be the first metastatic site after resection of the primary cancer; (2) there should be only one metastatic tumor at the time of thoracotomy; and (3) there should be no metastatic hilar or mediastinal lymph nodes. The survivals at 5 years and 10 years for 69 patients who satisfied these three criteria were $62.1 \%$ and $47.0 \%$, respectively (Fig. 7). The survivals at 5 years and 10 years for the 90 patients who did not satisfy these criteria were $22.4 \%$ and $10.6 \%$, respectively. There was a statistically significant difference between these two groups $(p<0.0001)$. 


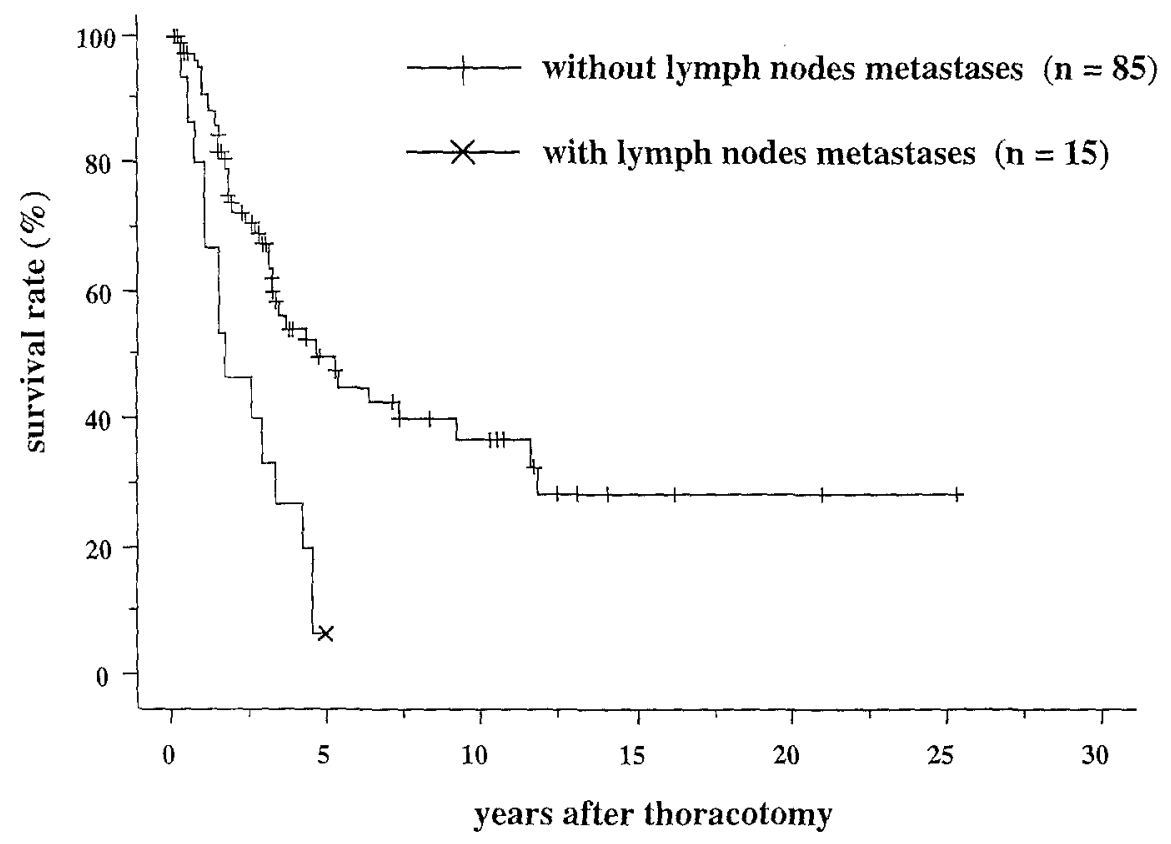

Fig. 5. Kaplan-Meier survival curves for patients with or without hilar and/or mediastinal lymph node metastases $(p=0.0004) n$, Number of patients.

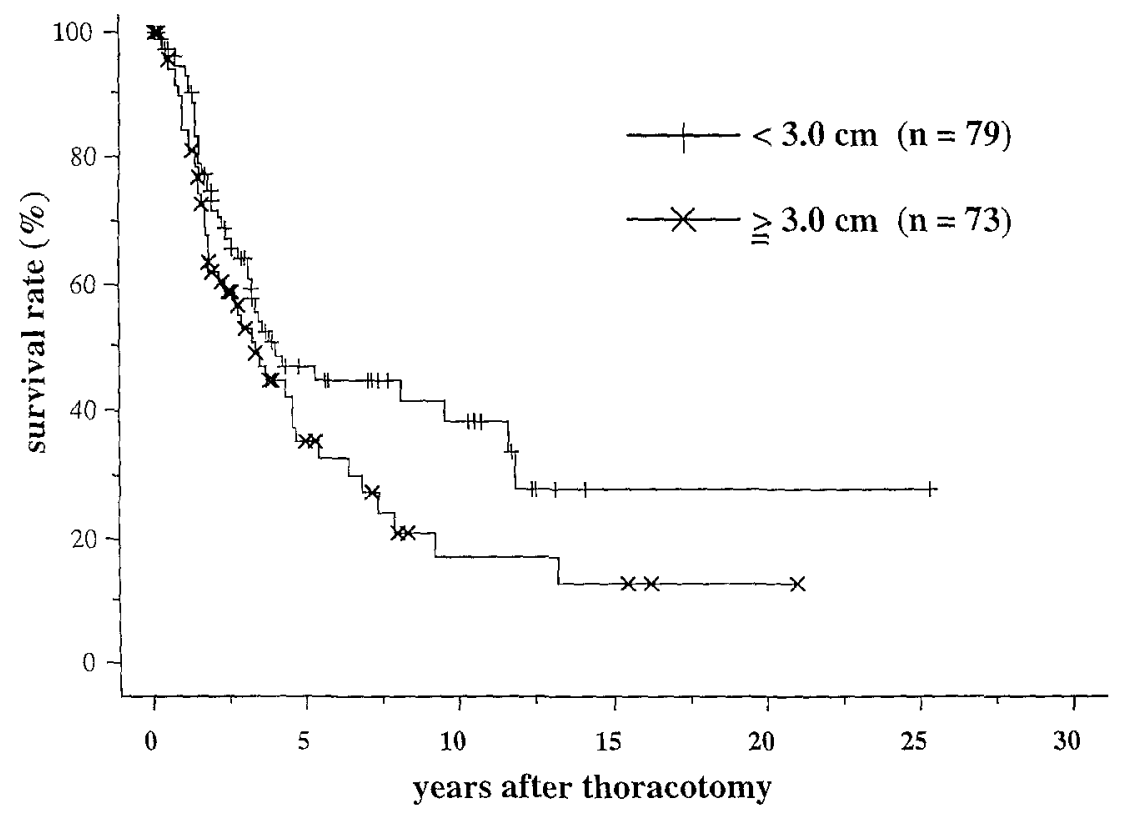

Fig. 6. Kaplan-Meier survival curves according to the size of the pulmonary metastasis $(>3.0 \mathrm{~cm}$ vs. $<3.0$ $\mathrm{cm})(p=0.078) . n$, Number of patients.

\section{Discussion}

The cumulative survivals for the 159 patients involved in this study at 5 years and at 10 years were $40.5 \%$ and $27.7 \%$, respectively. These survivals are not dramatically different from those in earlier reports. ${ }^{2-10}$ Wagner and colleagues ${ }^{13}$ reported on the significance of resection of hepatic metastases from colorectal cancer based on the difference between the clinical courses of patients with untreated metastases and those with resected metastases. 


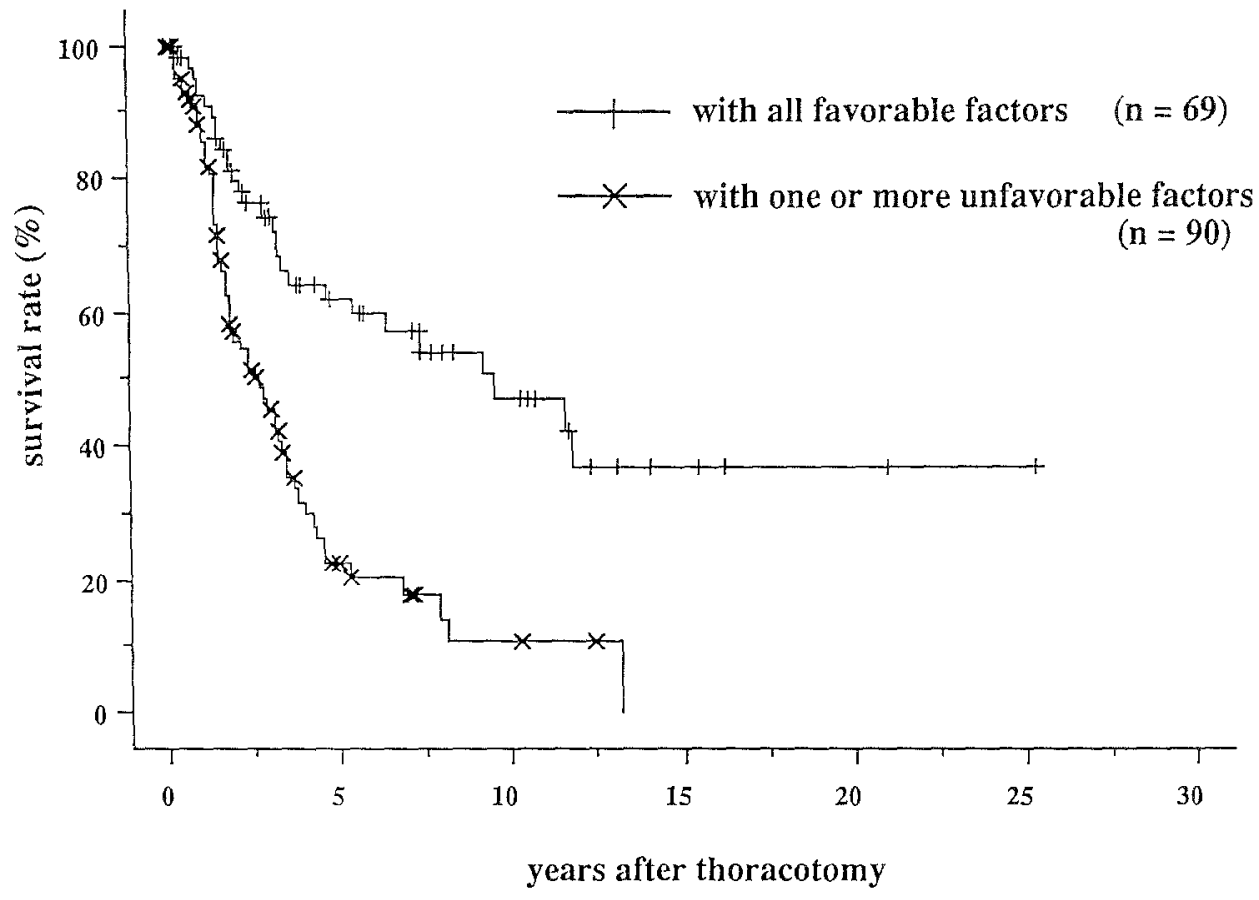

Fig. 7. Kaplan-Meier survival curves for 69 patients who satisfied the favorable three criteria given in the text and 90 patients who did not $(p<0.0001)$.

There have been no similar reports on pulmonary metastases or any prospective trials. $\mathrm{We}^{7}$ also suggested that the survival of the individual patient might be predetermined by the biologic behavior of the primary tumor, or "length bias." Therefore is it not possible to determine the significance of resection of pulmonary metastases from colorectal cancer. Although several patients died of metastatic tumors in 5 to 10 years, 15 patients in this series were alive after more than 10 years with no evidence of cancer recurrence. In addition, 69 patients with favorable factors in our experience had a cumulative survivals of $62.1 \%$ and $47.0 \%$ at 5 years and 10 years, respectively (Fig. 7). In light of these results, surgical treatment for pulmonary metastases from colorectal cancer not only may have some survival benefit but also may allow potential cure in selected patients.

Although Thomford, Wollner, and Clagett ${ }^{1}$ excluded patients with extrapulmonary metastases as candidates for thoracotomy, there have been several reports about pulmonary resection for patients with extrapulmonary metastases. McAfee and colleagues $^{8}$ said that the presence of resectable extrapulmonary metastases before or at the time of thoracotomy was not associated with a decreased survival. Yano and colleagues ${ }^{9}$ also reported that the presence of resectable or controllable hepatic metastases did not decrease the survival. In our series, the presence of extrapulmonary metastases was the unfavorable prognostic factor. This difference was probably caused by the differences in the number of patients, the periods of follow-up, and the indications for resection. Muhe, Gall, and Angemann ${ }^{14}$ reported the follow-up data of 67 patients who underwent resection for pulmonary metastases from colorectal cancer. That study included 18 patients who had hepatic metastases before thoracotomy, and their 5-year survival was only $18 \%$. The 5 -year survival for patients who underwent hepatic resection for metastases for colorectal cancer ranged from $25 \%$ to $47.9 \% .^{15-17}$ In light of these results, metastatectomy might be beneficial only when the metastasis is confined to the organ that is the first hematogenic metastatic filter from the primary tumor, and it might be of no effect when the secondary metastasis from the first filter organ occurs or when two filter organs of different pathways are affected. However, in our series the cumulative survival at 5 years for 22 patients with a solitary metastasis in group B was as high as $43.7 \%$. At present, it appears that a patient with a solitary pulmonary metastasis potentially benefits from pulmonary resection even when there 
is a history of hepatic metastasis. Regarding multiple pulmonary metastases in patients who have or had hepatic metastases, the significance of surgical treatment is still unknown. Therefore a prospective studies should be done to determine the significance of resection of pulmonary metastases for patients with extrapulmonary metastases.

As for the extent of pulmonary resection, our preliminary analysis in the middle of the 1980s showed a high incidence (about 30\%) of local recurrence at the resected margin in the cases of limited resection. In view of this, we attempted to perform lobectomy in all patients with solitary pulmonary metastases who were expected to have a favorable prognosis. However, the results of this series, as well as of our former report, ${ }^{7}$ show that the extent of pulmonary resection did not appear to affect the prognosis. Limited resection may be a preferable procedure for pulmonary metastatectomy if there is an adequate surgical margin around the tumor.

Cahan, Gastro, and Hajdu ${ }^{18}$ found that 10 of 20 patients who underwent resection for pulmonary metastases from colon had hilar or mediastinal lymph node metastases (or both). On the basis of this finding, they advocated lobectomy and lymph node removal for these metastatic lesions. However, in their series, only one patient with metastatic lymph nodes survived more than 5 years. In our series, resecting pulmonary metastases was not worth while in the patients who had hilar or mediastinal lymph nodes metastases, because the dissection of hilar and mediastinal lymph nodes could not control the disease. We believe that pulmonary metastasis with subsequent lymph node metastasis is in advance of the first step in the "metastatic cascade" advocated by Viadana, Bross, and Pickren. ${ }^{19}$ Therefore evaluation of hilar and mediastinal lymph nodes is important, and only sampling of those lymph nodes should be attempted to predict the clinical course after thoracotomy.

In conclusion, we believe that pulmonary resection for metastatic tumors from colorectal cancer can improve survival. Furthermore, there appears to be a chance for cure in selected patients with a solitary pulmonary metastasis. Pulmonary metastatectomy has a potential survival benefit to the patient who has multiple pulmonary metastases or who had hepatic metastases before thoracotomy.

\section{REFERENCES}

1. Thomford NR, Woolner LB, Clagett $T$. The surgical treatment of metastatic tumors in the lung. $\mathrm{J}$ Thorac Cardiovasc Surg 1965;49:357-63.

2. McCormack PM, Attiyeh FF. Resected pulmonary metastases from colorectal cancer. Dis Colon Rectum 1979;22:536-6.

3. Mountain CF, McMurtrey MJ, Hermes KE. Surgery for pulmonary metastasis: a 20-year experience. Ann Thorac Surg 984;38:323-30.

4. Mansel JK, Zinsmeister AR, Pairolero PC, Jett R. Pulmonary resection of metastatic colorectal adenocarcinoma: a ten-year experience. Chest 1986;30:109-12.

5. Phil E, Hughes ES, McDermott FT, Johnson WR, Katrivesis H. Lung recurrence after curative surgery for colorectal cancer. Dis Colon Rectum 1987;30:417-9.

6. Brister SJ, De Varennes B, Gordon PH, Sheiner NM, Pym J. Contemporary operative management of pulmonary metastases of colorectal origin. Dis Colon Rectum 1988;31:786-92.

7. Goya T, Miyazawa N, Kondo H, Tsuchiya R, Naruke T, Suemasu K. Surgical resection of pulmonary metastases from colorectal cancer: 10-year follow-up. Cancer 1989;64:141821.

8. McAfee MK, Allen MS, Trastek VF, Ilstrup DM, Deschamps C, Pairolero PC. Colorectal lung metastases: results of surgical excision. Ann Thorac Surg 1992;53:780-6.

9. Yano $T$, Hara $N$, Ichinose $Y$, Yokoyama $H$, Miura $T$, Ohta M. Results of pulmonary resection of metastatic colorectal cancer and its application. $J$ Thorac Cardiovasc Surg 1993; 106:875-9.

10. Wilking N, Petrelli NJ, Herrere L, Regal AM, Mittelman A. Surgical resection of pulmonary metastases from colorectal adenocarcinoma. Dis Colon Rectum 1985;28:562-4.

11. Kaplan EL, Meier P. Nonparametric estimation from incomplete observations. J Am Stat Assoc 1958;53:457-81.

12. Peteo R, Peteo J. Asymptomaticlly efficient rank and in variant procedures. J R Stat $\operatorname{Soc}(A)$ 1972;135:185-207.

13. Wagner JS, Adoson MA, Van Heerden JA, Adson MH, Ilstrup DM. The natural history of hepatic metastases from colorectal cancer. Ann Surg 1984;199:502-8.

14. Muhe E, Gall FP, Angemann B. Surgical treatment of metastases to lung and liver. Surg Gynecol Obstet 1981;152: 211-4.

15. Nordlinger B, Parc R, Delva E, Quilichini M, Hannoun L, Huguet $C$. Hepatic resection for colorectal liver metastases. Ann Surg 1987;205:256-63.

16. Fortner JG. Recurrence of colorectal cancer after hepatic resection. Am J Surg 1988;155:378-82.

17. Sugihara K, Hojo K, Moriya Y, Yamasaki S, Kosuge T, Takayama T. Pattern of recurrence after hepatic resection for colorectal metastases. Br J Surg 1993;80:1032-5.

18. Cahan WG, Gastro EB, Hajdu SI. Therapeutic pulmonary resection of colonic carcinoma metastatic to lung. Dis Colon Rectum 1974;17:302-9.

19. Viadana E, Bross IJD, Pickren KW. Cascade spread of blood-borne metastases in solid and nonsolid cancers of human. In: Weiss I, Gilbert HA, editors: Pulmonary metastasis. Boston: Hall, 1978:142-67. 